extra finance of multiple hospital visits, car parking charges and ever increasing cost of fuel, often in our area up to a hundred miles for a round trip to access a regional centre care.

To make additional decisions around the possible loss of a number of teeth, or in some cases a posterior dental clearance, to reduce the risk of BRONJ and cope with the treatment can be one decision too many with which to cope. A significant amount of time is usually required to give appropriate holistic and pastoral support for their decision making. Then to add to this that they need to pay for the 'privilege' of receiving this care, I think is of concern. I am not suggesting that dental treatment should be free for life as the constraints on funding for NHS care are of course significant for the foreseeable future. However, free dental care for their time of most need would seem appropriate in my eyes.

G. Greenwood By email

DOI: 10.1038/sj.bdj.2012.731

\section{FLAWED PENSION SCHEMES}

Sir, career average earnings pension schemes seem acceptable for general dental practitioners considering most of us will wind down in our older years of working life. This system is great in theory but in practice the system is flawed, especially for GDP associates.

The annual reconciliation report (ARR) is a declaration by the principal regarding the associate's pensionable earnings for that year alongside their own. We place our trust in principals to complete these declarations accurately and honestly. A discrepancy between declared and actual pensionable earnings may result in the associate receiving less pension than their entitlement.

Having experienced this several times, GDPs should be urged to check their schedules and check with NHS BSA that the correct figures have been declared for their performer number.

Miscalculations are being made either through principals' lack of understanding of NHS pension rules or through fraudulent behaviour. Despite much publicity from the BDA about this, it seems many NHS associates have not taken it upon themselves to firstly verify their declared earnings let alone challenge it if a discrepancy is noted. The pension one accrues as a GDP is wholly dependent on the figures entered on these forms.

Informal discussions with numerous dental associates leads to me to believe that the majority of them place no great emphasis on pensions either through ignorance or lack of understanding. This may ultimately be detrimental to their pension fund yet be an additional 'unearned bonus' to their principals.

\section{J. Balachandran}

By email

DOI: 10.1038/sj.bdj.2012.732

\section{UNJUSTIFIED VINDICTIVENESS}

Sir, there is anger and frustration nationally about the role of NHS Choices and the frustrating lack of editing rights and ability to challenge comments put on there. I would like to update your readers regarding our recent experience with a vindictive patient who commented adversely and unfavourably towards us.

We had not had any comments put on NHS Choices until recently when a patient of our practice was denied access to NHS services as they had failed to attend repeated appointments. Under our agreed policy with the PCT (in contract) we were allowed a 'two strikes and you are out'. The patient came in and gave my manager grief over this issue. Alerted by the commotion of the patient's raised voice, I remained hidden within earshot to listen to the conversation. My manager behaved remarkably coolly and in line with our difficult client management training, organised by our PCT! The patient left and said that she would let it be known that we were a rubbish practice.

Two days later we were statutorily informed by the PCT that a comment had been placed on the NHS Choices website. The comments were awful, saying that the staff were rude and impolite and so on. These are not reflective of our practice. The adverse comments are easily visible to any prospective new patient and only two clicks away when you Google our practice and my name. We obviously knew who it was.
We had previously carried out three patient surveys/audits in the past five years, two in-house and one independently carried out by Dr Foster Intelligence on behalf of our PCT over a six month period. In all three surveys we scored above 90\% satisfaction across of all areas of patient contact with our practice.

I contacted the moderator of NHS Choices and put my case across, outlining our good feedback history and applied to have the comment struck off as it was clearly unjustified vindictiveness against us. The request was denied and I was told it has to remain; to this day it is still there. Having heard from my LDC that this was an ongoing frustration with other GDPs nationally, I decided to do something about it. The only way was to drown the patient's comments by proactively asking patients in the subsequent week if they would comment on NHS Choices about their experience with us.

I was then contacted by the PCT informing me that I was an outlier in the high volume of comments on NHS Choices which were positive. I was informed that they would not likely be allowed to remain. I was livid! This is unfair! After explaining the issue, I asked for the details of the ombudsman overseeing NHS Choices. As I said I would take this further it looks like the PCT have now decided to allow the positive comments to remain.

We have successfully drowned the adverse comments in a sea of praise about 18 clicks deep.

This whole episode questions the value of NHS Choices. I have had to resort to gamesmanship to challenge someone else's unjustified comments and protect our reputation.

M. Hussain

Catford

DOI: 10.1038/sj.bdj.2012.733

\section{GUN PELLET RADIOPACITY}

Sir, a 51-year-old patient was referred to the maxillofacial department by his general dental practitioner due to 'an object lodged between UL7 and UL8'. On attendance he gave no history of injury to the area, and was symptomless. On examination it was noted there was a 